\title{
Beyond Coursework: Developing Communities in an Online Program of Study
}

\author{
Jodi Oakman \\ La Trobe University, Victoria, Australia
}

j.oakman@latrobe.edu.au

\begin{abstract}
The nexus between paid work and study is important. Developing opportunities to facilitate this link is a key part of good course design especially in postgraduate programs. Strong communities of practice can also assist with improving links between research and practice. The online study environment affords some challenges to achieving these goals. The current study proposes that offering formalised interaction points - synchronous or asynchronous - during online study, is critical to facilitating the link between work and study. Twenty-five graduates of a postgraduate program were interviewed to explore their experiences of an online program of study. Three key themes emerged and are described in this paper: engaging with study, building a new framework for my practice, and implementing changes to my practice. Online learning programs need to embed opportunities for interaction that are meaningful and allow for development of ideas and discussion, aiming to take learning beyond the program of study.
\end{abstract}

Keywords: distance education, community of practice, interactions, online learning, network

\section{Background}

The online learning space has evolved significantly since its inception in the 1990s, and increasing number of students are choosing this mode of study (Naidu, 2013). Changes to technology and improved Internet connection have created opportunities for universities that did not previously exist. A program of online courses creates a much broader market for universities (Holzweiss, Joyner, Fuller, Henderson, \& Young, 2014) and an ability to offer courses both nationally and internationally. This has particular appeal in the postgraduate market where prospective students are less likely to relocate for educational purposes due to career pathways, caring responsibilities, or other lifestyle factors (Jin, 2005). For these postgraduate students, online learning offers opportunities to study in specialist areas that may not be available at local institutions, in addition to providing flexibility to study at times outside working hours and other commitments. However, some challenges exist in online programs, such as the provision of good quality interaction opportunities and the availability of mechanisms for students to develop com-

(CC BY-NC 4.0) This article is licensed to you under a Creative Commons AttributionNonCommercial 4.0 International License. When you copy and redistribute this paper in full or in part, you need to provide proper attribution to it to ensure that others can later locate this work (and to ensure that others do not accuse you of plagiarism). You may (and we encourage you to) adapt, remix, transform, and build upon the material for any non-commercial purposes. This license does not permit you to use this material for commercial purposes. munities and networks for study and beyond. The focus of the current study was to investigate the value of interactions in an online program for supporting the development of communities of practice in the workplace. A further intention was to foster an ongoing commitment to learning around a shared domain and the use of this knowledge in a work environment.

A frequently lamented limitation of the online learning space is the lack of face-to-face interaction 
with students and lecturers and the networking opportunities - formal and informal. However, the availability of online technology options to develop connections between students and lecturers, and with each other, through the provision of interaction points (Bernard et al., 2009; Mohamed, 2008), has increased dramatically over the past decade. Using these technologies in ways that enables students to meaningfully connect with each other and develop a community of practice (Mackey \& Evans, 2011; Wenger, Trayner, \& de Laat, 2011) is an important outcome for education programs involving practitioners coming together for a common purpose.

Unfortunately, the move to increased numbers of online courses is often financially driven as it is considered a cheaper alternative compared to face-to-face options, despite evidence to the contrary (Smith \& Mitry, 2008). Good quality courses - online or face-to-face (Trigwell, Martin, Benjamin, \& Prosser, 2000) - require careful, evidence driven development, and the inclusion of interaction points has been supported (Rovai \& Barnum, 2003), but deeper insights are needed to understand the role of good quality interaction points in program design and how these fit with student needs.

\section{Current Study}

Recently, the wider professional Occupational Health and Safety (OHS) community in Australia has undertaken a substantial project to enhance the quality of OHS practice (HaSPA, 2012). This project developed and documented the "core body of knowledge" (BOK) required for all generalist OHS professionals. As a result of this project and a broader understanding of the need for professionals working in the field to be adequately skilled to manage contemporary workplace issues, the demand for OHS professionals to have postgraduate qualifications has increased.

The current study focused on a postgraduate program which trains professionals in the Ergonomics, Safety, and Health field (ESH) and covers two broad practice areas: Occupational Health and Safety (OHS) and Ergonomics. ESH Professionals provide advice on the prevention and minimisation of work-related fatality, injury, disease, and ill health. Professionals in ESH work in a wide range of organisations and industry settings and are required to understand the complexity and variability of human behaviour and to have a technical understanding of workplace hazards and work processes with the ability to interpret interface issues between people, equipment, and environments. Postgraduate students enrolled in the program may have extensive work experience but limited formal training in the field. Developing links between the work experience and providing theoretical knowledge to underpin and extend this knowledge is important and the online course design enables students to engage with study whilst continuing their employment. To support this integration of theory and practice the development of a community to discuss and debate contemporary workplace issues is important. The extent to which offering interaction points across a program facilitates these broad aims requires investigation of graduates' experiences, which will enable exploration of their voices to address two important questions:

- Do interaction opportunities in an online program enable students to link theoretical knowledge with their workplace situations?

- Can interaction points in an online program assist students to develop a community of practice?

\section{Literature Review}

\section{Interactions and links with learning}

Interactions in online learning can be either synchronous or asynchronous. Situations where lecturers and students are online and participating in "real time" lectures or discussions are considered synchronous. On the other hand, asynchronous interactions occur when students make com- 
munications in their own time such as using online discussions to make comments or answer questions posed by the lecturer or fellow students (Biggs \& Tang, 2011). Both offer opportunities to build and extend links between theory and workplace practice. Moore's (1989) framework to define interactions in distance education provides a useful basis for conceptualizing and designing such points in the course where information exchange can occur. Moore defined three forms of interaction in distance education (DE) - learner-content, learner-instructor, and learner-learner to assist with clearer distinctions in DE. An addition to Moore's framework was made by Hillman, Willis, and Gunawardena (1994) called learner-interface interaction, which reflected the changing nature of DE and the increased usage of online communication tools; linking these with learning outcomes needs considered integration.

Sfard (1998) outlines two metaphors for learning - acquisition and participation - to guide the work of learners, teachers, and researchers. Providing opportunities for knowledge acquisition in an online course is relatively straightforward; provision of materials through teaching sites is made available to students for downloading, who can read and learn the relevant material. However, if the aim of the course is to integrate students and their work experience, sufficient opportunities must be offered to enable participation to occur. Interaction points offer opportunities for discussion and debate on linking theory to workplace experience. Different aspects of learning are approached with acquisition and participation - both fundamental inclusions in good course design.

\section{Interactions and student outcomes}

If interactions are considered as potential learning spaces for online courses and enable an environment for students to learn from each other, the course material, and the instructor, success of these interaction points requires a multifactorial view of student outcomes. Measurable outcomes might include final grades, student satisfaction levels, and the ability to analyse and interpret problems using skill and knowledge gained during the course of study. Other outcomes might include creating a community of practice to encourage learning and sharing of information (Wenger et al., 2011), collective problem solving (Garrison, Anderson, \& Archer, 2001) and help develop a culture of life-long learning (Candy, 2000).

The literature is unequivocal about the importance of the interactions in online courses for satisfaction and motivation (Bernard et al., 2009; Cho, 2011; Cook et al., 2010; Little, Passmore, \& Schullo, 2006; Wong, Greenhalgh, \& Pawson, 2010). Links between grades and interactions are less clear, some reporting a positive association (Lee \& Rha, 2009) whilst others have found no association (Frith \& Kee, 2003). One meta analysis (Bernard et al., 2009) examined different models of distance education and found online courses that incorporated some level of interaction in the course design resulted in improved student learning. Gallie (2005) reported significant numbers of students receiving a pass or higher grade after redesigning an online occupational health and safety course to encourage student-student and student-instructor interaction. Increases in grades were not equal for all students; no significant change was found for those already achieving higher grades.

Satisfaction levels, measured through student feedback, with online courses offering synchronous sessions have been reported to be higher than those without (Frith \& Kee, 2003; Little et al., 2006). However, interaction should not be viewed as a substitute for poor course materials (Lee $\&$ Rha, 2009). Some have reported that students enrolled in interactive online courses perform better in tests of critical learning than those who have little interaction with their peers or educators (Lee \& Rha, 2009). However, this is not supported by all and requires further investigation. An extensive systematic review by Cook and colleagues (2010) found that satisfaction was linked to the following: the provision of interaction opportunities, practical exercises, repetition, feedback, and audio (interaction via voice rather than through email/text). Richardson and Swan 
(2003) reported that students who perceived a high level of social presence were more likely to report higher perceived learning and satisfaction with the instructor.

\section{The purpose of interaction}

A common complaint from students enrolled in online courses is isolation and lack of opportunity for communication with their peers (Fox, O'Rourke, Roberts, \& Walker, 2001). Chen (2003) suggests 4 key factors are important for the success of networked learning communities: "interactivity, opportunities for collaborations, a meaningful and motivating context and a continuously available learning environment" (p.36). Enhanced collaboration encourages a social network and greater motivation and opportunities to articulate, discuss, and reflect on their learning strategies and changes associated with learning (Chen, 2003). In providing opportunities for interaction a context can be explored in greater depth than without them.

The nexus between paid work and learning is also important (Billett, Smith, \& Barkers, 2005). Offering students the opportunity to apply theoretical knowledge to workplace situations is of key importance in postgraduate courses and challenges exist in achieving this in both a classroom and an online environment. Facilitated interaction points embedded in course design offer opportunities for students to formalize these links between theory and workplace practice. An additional advantage is the "meeting" of fellow students and the ability to develop communities around their profession. Whilst universities are actively pursuing an increase to the number of online courses, the delivery mode must not be at the expense of participation and community development. Course designers and coordinators must ensure that appropriate opportunities are embedded in course design and that they meet the needs of the student population. The needs are different across courses but many vocationally orientated courses aiming to actively encourage a strong nexus between work and learning will need to seek and utilise appropriate options to manage these in virtual environments.

\section{Communities and networks}

Wenger and colleagues' (2011) notion of a community of practice describes a collective intention to foster a domain of knowledge and to sustain learning about it. This provides a useful framework to underpin educational design principles for online programs and informing decisions around development of interaction points. The notion of community of practice has been extensively described and debated but is beyond the scope of the current study (Gherardi, 2013). For the purpose of the current study, a community of practice is considered as looking beyond the course curriculum to the profession and the development of strong links between the two. Study programs comprising a range of practitioners in their respective fields with a broad collective work experience often highly relevant to the course material are ideally placed to provide foundations for the development of a community of practice. "Community provides a social space where participants can discover and further a learning partnership related to a common domain"

(Wenger et al., 2011, p 10).

Networks, often coexisting with communities, are primarily focused on optimizing connectivity among the group. In comparison, communities are focused on the learning partnership and development of identity around a common agenda. The current study is focused on community development, but networks are likely to coexist within the populations, particularly given the shared professional identity of the students.

In contemporary work environments, developing strong communities and networks of fellow professionals provides important resources to draw upon for problem solving, mentoring, and sharing of new information. For graduates, these networks and communities can facilitate learning beyond their formalised degree program. Further exploration of the development of communities and networks is needed to provide insight into how the creation of space within and alongside 
academic programs might facilitate these important processes (Mackey \& Evans, 2011). Downes (2006) suggests that discussions and interactions are shaped by the content and curriculum and that communities do not often extend beyond the course. If the intent is to foster communities and networks to encourage life long learning and commitment to evidence informed workplace practice there is merit in encouraging development of strong communities of practice which extend beyond the program of study.

\section{Method}

To advance our understanding of the value of interactions in an online program, graduate opinions were sought. These opinions were analysed in order to consider the impact of offering interactions both during and after the formal program. Interactions were considered as formal arrangements and included as part of the program design, such as online interactive sessions or discussion boards, and informal, such as those made by students to discuss their study or workplace practice issues.

\section{Sample Population}

This was a qualitative study undertaken in the Centre for Ergonomics and Human Factors located within the Faculty of Health Sciences, in an Australian based University. Participants were graduates of a fully online postgraduate program in Ergonomics, Safety and Health (ESH), which commenced in 2010. The program comprises a Graduate Certificate and Masters level qualification. A qualitative study design was undertaken to enable a deeper exploration of the student experience.

All graduates from the program between 2010-2012 were sent an email inviting them to participate in a research project. Graduates that responded to the invite were sent detailed information and a consent form to complete prior to the interview. Participants comprised 12 Graduate Certificate (GC) and 13 Masters (M) graduates. University ethics approval was obtained (FHEC13/070).

\section{Interaction Points}

Each subject within the program offered a weekly synchronous online session (interaction point) through Blackboard Collaborate software, Version 12 (Blackboard Inc.) held in the evening for approximately one hour. Prior to each session students were provided with a range of questions related to theoretical content covered in the previous week. Questions were aimed at the application of theoretical material into workplace examples. Students were advised to prepare for these sessions and to have considered the application of subject material in settings they are familiar with. The coordinator facilitated the weekly sessions but the focus was on student contribution and dialogue between students. Sessions were recorded for those students unable to attend.

In addition to the synchronous sessions, asynchronous online questions/topics were posted on a fortnightly basis across the semester to explore a range of workplace issues in relation to course content. Whilst the questions were different from the synchronous session questions, the focus remained on the application of theory in workplace settings, asking students to consider a range of issues and how they might use an evidence informed approach to manage particular workplace situations.

\section{Interviews}

In order to address the study questions a semi-structured interview was conducted with each of 25 graduates who responded. Telephone interviews took between 30-60 minutes. 
Interview questions were derived from analysis of relevant literature concerning online courses and informal discussions with students on the issues that were of importance to them in undertaking postgraduate study. A semi-structured approach was employed to allow flexibility in questions and responses, and general topic areas included their experiences with online learning, the impact of learning on workplace practices and which aspects of the course were most beneficial for learning, preferred methods of accessing course materials, and their views on the synchronous sessions. A member of the research team, not involved in the teaching program, undertook all interviews. All interviews were recorded and transcribed verbatim. Following transcription, all identifiable material was removed to protect the confidentiality of the participants. NVivo Version 10 software was used to assist with data management and the categorisation and coding process. Interviews were analysed thematically with the use of memo writing to assist with analysis of emerging categories (Charmaz, 2014). Themes and sub themes were developed following categorisation of the data (Braun \& Clarke, 2006). The coding process was done iteratively, as the coding process was undertaken, with discussion between the research team of the emerging categories and themes. Results were discussed with those involved in teaching of the ESH program to assist with validity and interpretation of the findings.

\section{Results}

All participants enrolled in the postgraduate program came with a history of work and study in a range of discipline areas. Three key themes emerged: engaging with study, building a new framework for my practice, and implementing changes to my practice. A number of sub-themes were also developed and are described within the relevant themes (see Table 1).

\section{Table 1 Themes and sub themes}

\begin{tabular}{lll} 
Engaging with study & $\begin{array}{l}\text { Building a new framework for } \\
\text { my practice }\end{array}$ & $\begin{array}{l}\text { Implementing changes to my } \\
\text { practice }\end{array}$ \\
\hline Flexibility & $\begin{array}{l}\text { Developing a new professional } \\
\text { identity }\end{array}$ \\
$\begin{array}{l}\text { Developing networks with } \\
\text { students }\end{array}$ & $\begin{array}{l}\text { The role of study in facilitating } \\
\text { a changing professional identi- } \\
\text { ty }\end{array}$ \\
Design of the course &
\end{tabular}

\section{Engaging with Study}

Engaging with study emerged as a key theme from the data collected and reflects students' perceptions of their study experience. Sub themes within the theme included flexibility, developing networks with students, and design of the course. Some students relished the overall study experience and the intellectual stimulation, whilst others reported the experience of studying and working along with managing personal commitments very challenging. Students reflected on the flexibility of online learning but recognised that whilst this mode of delivery offered benefits there were also negatives. In particular, some students found online studying isolating and missed the face-to-face lecture experience. However, the majority of graduates found the flexibility afforded by the online nature of the course far outweighed any negatives and recognised there were inbuilt opportunities - online and face-to-face - within the study program to encourage building networks with other students.

Although most graduates rated flexibility very highly, it needed to be in combination with good quality content. "I appreciated the flexibility of the delivery method, but the content itself was 
very interesting and appropriate and really set a good [standard], I suppose theory underpinning the practice" (GC_23).

In the sub theme, developing networks with students, students reflected on the opportunities for interactions with their fellow students. Synchronous "real time" interactions provided opportunities to discuss the application of course theory to contemporary workplace issue, on a weekly basis. Graduates tended to have dichotomous views of these online sessions, being either committed attenders or those who made a decision not to attend for a variety of reasons, which included session timing or a perceived lack of relevance. These interactions were more highly valued by some than others. This graduate enjoyed the human interaction, "I think just human interaction was good...to get their [other students] experience and stuff in a live environment" (GC_28). For some it helped in building professional networks and community:

I still felt that I had that close contact with the lecturers and with other students. So even though I have met very few of them there's still a community as such and the delivery methods helped that and each of the lecturers did help that too by encouraging communication. (GC_23)

However, some found they missed the incidental informal contact with peers in face-to-face options as indicated by this student:

I think for me probably the hardest thing was that you don't really have much contact with the other students or if you do, it's more in a formal setting like, you know, a session on the (internet), you know, with the lecturer present. (M_25)

The ability to share information with others and gather new ideas was commonly reported as a positive outcome of the synchronous sessions:

To hear the views of other people who are working in completely different fields, added another level of interest, and also just get different people's perspectives is always another way of learning. (GC_23)

Those graduates who attended felt the synchronous sessions were worthwhile but would have preferred higher attendance rates by their peers, "some students just didn't engage and some weeks there would be like two or three of us, which was disappointing" (M_6). However, the same graduate also said, "other weeks we'd have amazing discussions, you know, six of us on the line and people would talk about all different sorts of things" (M_6). Conversely, all graduates did not find the online sessions congruent with their personal learning style:

A couple of those [sessions] that I attended I probably didn't get a heap out of... I found it impossible, I'm just somebody who likes to get that stuff in my own time and just work through it, so there weren't too many negatives in there. (M_9)

Using a system that allowed recording of the sessions was important so that students had the option to listen at a later time, and it provided flexibility valued by graduates, as illustrated by this one, "because it's recorded I can access it anytime, that's a great thing. So I can listen back to the tute and get the information" (M_2). Some found the sessions great but ran out of time to attend, and then felt they weren't pulling their weight, as this graduate highlighted:

Absolutely awesome [the online sessions], however I feel kind of selfish in saying that, I didn't' attend towards the end of last year and this year, the effort of the other students, you know, I kind of leeched on their work, and I feel bad. (GC_3)

Students referred to the importance of course design and how expectations from lecturers and fellow students impacted their experiences. A further challenge highlighted by individuals was the need to prepare for sessions, this required commitment and a dual responsibility of students and lecturers. Although lecturers appear to take a passive role, skill was needed to facilitate an 
engaging and useful session, "I think certainly the lecturers were very good at teasing information from students" (M_10). And this graduate highlights a common issue, "well there was the expectation that you did the activities prior to that [session] and you know sometimes I did and sometimes I didn't" (GC_13). Preparation was important as this person also found, "I sort of found frustration [sic]s with myself in that when I get to an online session I may not have done all of the work the previous week and some sometimes I found discussion was over my head a bit" (M_7).

Asynchronous opportunities, such as the discussion boards, were valued by some graduates who found it useful to gain information for solving workplace problems: "we actually have discussion boards that were useful where other students might mention professional affiliations or documents" (M_6). The applied nature of the discussion board conversation was a common positive theme:

...I think [what] was underrated was the forums where you posted discussion topics...it gave you a really good feel, there's always the theory behind anything but then applying that to people's workplaces I found really interesting and there are a lot of diverse people like from nurses through to people in the mining industry, people in return to work.

(GC 28)

Some discussion boards were assessed and contributed to the final mark. However, not all graduates were happy with the process as highlighted by this graduate who felt that more direction was required: "I'm confused about is how many are required [contributions are needed] to [get] the full mark obviously it's the content you type as well" (GC_1).

\section{Building a New Framework for My Practice}

In building a new framework for my practice students reflected on the process of developing a new professional identity and the role of study in facilitating this change, in particular, the notion of learning to identify limitations in their current practice, how one might address problems in a new way, or taking a more evidence informed approach to decision making. Graduates spoke about using a range of different approaches to addressing their work and being open to a broader range of potential solutions:

A lot of the emerging risks that are common within our industry came up [in the course] and strategies, not exactly strategies on how to manage them but strategies on how to assess them and determining what's right for you, I think that was very beneficial, and that's definitely something that I have applied to my work. (GC_1)

Layering of information was considered important in helping to build frameworks to assist with problem solving and developing solutions to workplace issues:

There were good course materials that were provided and you could see there's a good thread and the way different topics are building on each other to give you that added knowledge and the skill base required....to give you that more analytical approach, I guess. (GC_18)

Relevancy to the field was frequently discussed and considered an important component of choosing and then completing the course. Nearly all graduates commented on finding the material covered relevant and applied in its focus, and it was applicable for their workplaces. The content was considered interesting and relevant, with the exception of one graduate who felt they could have been more challenged. Student interactions also helped with building new frameworks; the sharing of workplace issues during the weekly synchronous sessions enabled a range of views and practice interventions to be discussed and debated, as highlighted by this participant, "I still keep in touch with a couple of people ... which is just sort of resource that you can pick up the phone and go "hey any thoughts on this". (M_6) 
Thus, students were exposed to a greater range of situations through these discussions than could be provided by the lecturers. This collective approach was highly valued by many graduates but not all. Some graduates preferred to approach their knowledge acquisition in a more solitary manner, with little participation.

\section{Implementing Changes to My Practice}

Implementing changes to my practice was reported as a challenge by some graduates, in many cases linked to seniority of the job role that people were currently employed in. A disconnect between knowing what should be done and what was currently being done was a common theme and area of frustration for many graduates "I've got all this other knowledge and skills that I can offer that really isn't being drawn on" (M_10). A common reflection from graduates was that organisations were happy to continue doing what they had always done rather than make changes. Addressing organisational issues in relation to health and safety was seen as an important part of facilitating organisational change. This graduate is reflecting on how they are going to implement changes and use their knowledge:

I think it [the course] really helped me to move across into the industry whilst I was studying so that I could reflect on what I'm learning versus what's actually happening in the real world and how I might start to think about changing that. (M_22)

Reflection on practice was also viewed as important, "I'd have to say it's really changed the way I would look at running health and safety within an organisation" (M_22). The reflections of graduates really supported the translation of theory into practice; even though they faced challenges in making changes, graduates were active in developing strategies to improve workplace practice.

\section{Discussion}

The first research question in the study, "Do interaction opportunities in an online program enabling students to link theoretical knowledge with their workplace situation", was explored in detail. Many students commented on the role of the interactions - synchronous and asynchronousin developing links with others to discuss and debate different issues and to hear about different approaches for managing workplace problems. Mature aged students, such as the ones in this study, like to integrate learning with their work experience (Kahu, Stephens, Leach, \& Zepke, 2013), and the use of the weekly synchronous sessions enabled this to happen whilst providing opportunities for students to build professional networks and enjoy the development of a community of practice. The evidence from the interviews supports the notion that these work and learning links are occurring, as most of the graduates reflected on the use of knowledge and how, having completed the course, they had changed their approach to dealing with the problems they were managing in their workplaces. A common theme was the seeking and then use of evidence to inform decision-making or to develop an argument for change in their workplace.

A key goal of the program reviewed in the current study is the development of strong links between work and learning. The use of interaction opportunities in the program to develop a community of learning and further the development of professional networks, is intended to facilitate this nexus, an issue explored in the interviews with graduates to ascertain their views. The design of the interactions appears to successfully facilitate the work and learning interface, some students preferring asynchronous offerings and others the synchronous options, reinforcing the need for a range of options to capture different learning strategies.

The second question addressed by the study was, "Can interaction points in an online program assist students to develop a community of practice? Students undertake postgraduate study for a number of reasons and these should be considered in the context of the current study. For many 
students, personal satisfaction and new skill acquisition is an important consideration in their decision to undertake further study (Pratt, Hillier, \& Mace, 1999). For others, postgraduate study is related to a career change (Donaldson \& McNicholas, 2004). In Australia, a change in the certification process by the Safety Institute of Australia (SIA) now requires members to have a minimum relevant education level in Occupational Health and Safety (OHS). This has meant an increased demand for postgraduate courses in the field of OHS, such as the one in the current study. This change is part of a larger project to improve the quality of OHS professional practice in Australia (for further explanation see www.ohsbok.org.au). Building a sustainable community of practice is an important goal of the program, and the interaction points offered throughout the program are an important part of this development. An additional component to further the development of a community of practice has been the recent introduction of a blog coordinated by University staff, the impact of which has not yet been analysed.

The development of effective online communities requires a space for students where they can discuss concepts and ask questions of each other and the teacher in real time. The synchronous sessions were designed to provide that space and enable development of ideas and relationships to foster the notion of a community, student-centered approach, consistent with that proposed by Biggs and Tang (2011). The provision of formal interaction spaces in online courses enabled a social presence to be developed, consistent with that proposed by Chen (2003), and reported by participants in the current study as important in the development of networks with fellow students. These interactions afford opportunities consistent with Sfard's (1998) proposal of acquisition and participation, enabling students to engage with theory and knowledge through discussion and debate with other learners in their field, supporting the important role of these opportunities.

An additional benefit, identified in the study, to the synchronous sessions was the ability to solve problems immediately and talk through issues in real time. This was beneficial for both students and lecturers and an efficient way to ensure that material was understood and any misinterpretations clarified. Furthermore, the synchronous sessions enabled students to introduce ideas into discussion that provided feedback to lecturers on contemporary workplace issues, thus providing a learning loop, particularly important in courses strongly connected to rapidly changing work environments.

Communities of practice take time to develop and evolve. Evidence from the current study suggests this is occurring and students place a value on developing connections with their peers; therefore, the provision of mechanisms to ensure a range of interaction points are offered across the course is important. Effective learning is about conceptual change, and the challenge in online learning is to effectively communicate and motivate students to be able learn in a different environment to the traditional classroom. Providing students with opportunities to develop a social presence in an online environment is an important part of building approaches to deep inquiry, and are an important part of developing professionals and consistent with previous research (Garrison, Anderson, \& Archer, 2010). Results from this study suggest interactions were highly valued and are considered a point of difference between the course described in the current study and other programs where synchronous opportunities were not offered. These opportunities enabled debate and discussion of ideas and a deeper engagement through this interactive participation than could be developed without peer interaction. From a teaching perspective, observations from the interviews and noted by others (Bower, Kenney, Dalgarno, Lee, \& Kennedy, 2014), successful online synchronous sessions require appropriate use of support staff, extensive preparation, clear instructions and skilled facilitators (Baran, Correia, \& Thompson, 2011). The importance of such issues is not always well understood by University management who often view online courses as a cheaper alternative to traditional classroom methods, which can undermine claims for the resources required to develop and maintain high quality sessions. However, this 
does not discount the important role of other interaction points also discussed such as discussion boards, as these offer a different style of interaction and can be used to supplement learning.

\section{Study Limitations}

All studies have both strengths and weaknesses. The use of interviews in this study enabled collection of in depth views from graduates that would not have been possible with a quantitative approach. However, this limited the number of participants that could be included in the study. A further consideration is the issue of bias, and the use of an interviewer not involved with teaching in the program was undertaken to reduce this risk. This study was undertaken with graduates of a program in a particular discipline but the issues presented here potentially have relevancy for all those involved in teaching online programs within professional disciplines.

\section{Conclusions}

A challenge exists for course designers in how to incorporate meaningful interaction points that connect with the needs of contemporary student. The current study provides insights into the views of students enrolled in an online program of study and the role of interactions. These findings are not discipline specific and may be applicable to course developers in other fields. Further research exploring the sustainability of these communities of practice would be of interest.

The work-learning nexus is a critical component of postgraduate education in many programs. The boundaries around this particular interface are constantly shifting and require ongoing examination to ensure that teaching practices embrace the importance of participation in the learning experience for postgraduate students. Online learning should not be seen as a barrier to interactions. Technology options are rapidly changing and a range of options can be utilised to facilitate high quality interactions that are valued by students and help to build professional communities and networks, which extends beyond the coursework program.

\section{References}

Baran, E., Correia, A-P., \& Thompson, A. (2011). Transforming online teaching practice: Critical analysis of the literature on the roles and competencies of online teachers. Distance Education, 32(3), 421-439. doi: $10.1080 / 01587919.2011 .610293$

Bernard, R. M., Abrami, P., Borokhovski, E., Wade, C. A, Tamim, R., Surkes, M., \& Bethel, E. C. (2009). A meta-analysis of three types of interaction treatments in distance education. Review of Educational Research, 79(3), 1243-1289. doi: 10.3102/0034654309333844

Biggs, J., \& Tang, C. (2011). Teaching for quality learning at university. Maidenhead, England: Society for Research into Higher Education and Open University Press.

Billett, S., Smith, R., \& Barkers, M. (2005). Understanding work learning and the remaking of cultural practices. Studies in Continuing Education, 27(3), 219-237.

Bower, M., Kenney, J., Dalgarno, B., Lee, M., \& Kennedy, G. (2014). Patterns and principles for blended synchronous learning: Engaging remote and face-to-face learners in rich-media real-time collaborative activites. Australian Journal of Educational Technology, 30(3), 261-272.

Braun, V., \& Clarke, V. (2006). Using thematic analysis in psychology. Qualitative Research in Psychology, 3(2), 77-101.

Candy, P. (2000). Knowledge navigators and lifelong learning: Producing graduates for the information society. Higher Education Research and Development, 19(3), 261-277.

Charmaz, K. (2014). A constructivist grounded theory analysis of losing and regaining a valued self. In F. J. Wertz, K. Harmaz, L. M. McMullen, R. Josselson, R. Anderson, \& E. McSpadden (Eds.), Five ways of doing qualitative analysis. New York: Guildford. 
Chen, T. (2003). Recommendations for creating and maintaining effective networked learning communities: A review of the literature. International Journal of Instructional Media, 30(1), 35-44.

Cho, T-J. (2011). The impact of types of interaction on student satisfaction in online courses. International Journal on E-Learning, 10(2), 109-125.

Cook, D., Levinson, A. J., Garside, S., Dupras, D. M., Erwin, P. J., \& Montori, V. M. (2010). Instructional design variations in internet-based learning for health professions education: A systematic review and meta-analysis. Academic Medicine, 85(5), 909-922.

Donaldson, B., \& McNicholas, C. (2004). Understanding the postgraduate education market for UK-based students: A review and empirical study. International Journal of Nonprofit and Voluntary Sector Marketing, 9(4), 346-360. doi: 10.1002/nvsm.259

Downes, S. (2006). Learning networks and connective knowledge. Instructional Technology Forum, 28. Retrieved August 1, 2016, from http://it.coe.uga.edu/itforum/paper92/paper92.html.

Fox, N., O'Rourke, A., Roberts, C., \& Walker, J. (2001). Change management in primary care: Design and evaluation of an internet-delivered course. Medical Education, 35(8), 803-805. doi: 10.1046/j.13652923.2001.00974.x

Frith, K., \& Kee, C. (2003). The effect of communication on nursing student outcomes in a web-based course. Journal of Nursing Education, 42(8), 350-358.

Gallie, K. (2005). Student perceptions as distance learners in internet based courses. Studies in Learning, Evaluation, Innovation and Development, 2(3), 69-76.

Garrison, R., Anderson, T., \& Archer, W. (2001). Critical thinking, cognitive presence, and computer conferencing in distance education. American Journal of Distance Education, 15(1), 7-23.

Garrison, R., Anderson, T., \& Archer, W. (2010). The first decade of the community of inquiry framework: A retrospective. Internet and Higher Education, 13(1-2), 5-9.

Gherardi, S. (2013). Is organisational learning possible without participation? In S. Weber, M. Gohlich, A. Schroer, C. Fahrenwald, \& H. Macha (Eds.), Organiszation und Partizipation: Springer Fachmedien Wiesbaden.

HaSPA (Health and Safety Professionals Alliance). (2012). The core body of knowledge for generalist OHS professionals. Tullamarine, VIC, Safety Institute of Australia. Retrieved August 1, 2016, from http://www.ohsbok.org.au/download-the-body-of-knowledge/.

Hillman, D. C. A., Willis, D. J., \& Gunawardena, C. N. (1994). Learner-interface interaction in distance education: An extension of contemporary models and strategies for practitioners. American Journal of Distance Education, 8(2), 30-42. doi: 10.1080/08923649409526853

Holzweiss, P. C., Joyner, S. A., Fuller, M. B., Henderson, S., \& Young, R. (2014). Online graduate students' perceptions of best learning experiences. Distance Education, 35(3), 311-323. doi: $10.1080 / 01587919.2015 .955262$

Jin, S. (2005). Analyzing student-student and student-instructor interaction through multiple communication tools in web-based learning. International Journal of Instructional Media, 32(1), 59-67.

Kahu, E. R., Stephens, C., Leach, L., \& Zepke, N. (2013). The engagement of mature distance students. Higher Education Research \& Development, 32(5), 791-804. doi: 10.1080/07294360.2013.777036

Lee, H-J., \& Rha, I. (2009). Influence of structure and interaction on student achievement and satisfaction in web-based distance learning. Educational Technology \& Society, 12(4), 372-382.

Little, B. B., Passmore, D., \& Schullo, S. (2006). Using synchronous software in web-based nursing courses. Computers Informatics Nursing, 24(6), 317-325.

Mackey, J., \& Evans, T. (2011). Interconnecting networks of practice for professional learning. The International Review of Research in Open and Distributed Learning, 12(3). 
Mohamed, A. (2008). Foundations of educational theory for online learning. In T. Anderson (Ed.), The theory and practice of online learning (2nd ed., pp. 15-44). Athabasca CA: AU Press.

Moore, M. G. (1989). Editorial: Three types of interaction. American Journal of Distance Education, 3(2), 1-7. doi: 10.1080/08923648909526659

Naidu, S. (2013). Learning about learning and teaching online. Distance Education, 34(1), 1-3. doi: $10.1080 / 01587919.2013 .775715$

Pratt, J., Hillier, Y., \& Mace, J. (1999). Markets and motivation in part-time postgraduate education. Studies in Higher Education, 24(1), 95-107. doi: 10.1080/03075079912331380168

Richardson, J., \& Swan, K. (2003). Examining social presence in online courses in relation to students' perceived learning and satisfaction. IDEALS, University of Illinois at Springfield. Retrieved August 1, 2016, from http://hdl.handle.net/2142/18713

Rovai, A., \& Barnum, K. (2003). On-line course effectiveness: An analysis of student interactions and perceptions of learning. Journal of Distance Education, 18(1), 57-73.

Sfard, A. (1998). On two metaphors for learning and the dangers of choosing just one. Educational Researcher, 27(2), 4-13.

Smith, D. E., \& Mitry, D. J. (2008). Investigation of higher education: The real costs and quality of online programs. Journal of Education for Business, 83(3), 147-152.

Trigwell, K., Martin, E., Benjamin, J., \& Prosser, M. (2000). Scholarship of teaching: A model. Higher Education Research \& Development, 19(2), 155-168.

Wenger, E., Trayner, B., \& de Laat, M. (2011). Promoting and assessing value creation in communities and networks: A conceptual framework. Rapport 18, Ruud de Moor Centrum, Open University of the Netherlands. Retrieved August 1, 2016, from http://wengertrayner.com/resources/publications/evaluation-framework/.

Wong, G., Greenhalgh, T., \& Pawson, R. (2010). Internet-based medical education: A realist review of what works, for whom and in what circumstances. BMC Medical Education, 10(1), 10-12.

\section{Biography}

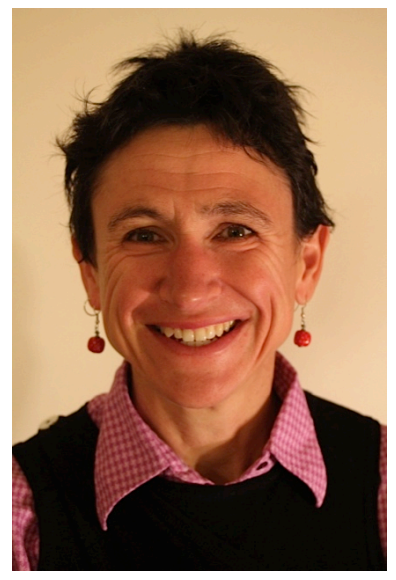

Jodi Oakman is a senior lecturer at the Centre for Ergonomics and Human Factors, La Trobe University and the postgraduate coordinator for the Ergonomics, Safety and Health program and Head of Department for Public Health. She is a qualified physiotherapist and has a $\mathrm{PhD}$ in the area of the ageing workforce and the impact of organisations on their employees' retirement intentions. She led the team who developed a fully online Masters program in the area of Ergonomics, Safety and Health and is committed to using technology to enable the delivery of high quality online education. 